\title{
EVALUATION OF THE POTENTIAL OF BIODIESEL 3G: HETEROTROPHIC BIOREACTORS
}

\author{
Lidiane Machado $^{1}$, Leila Queiroz Zepka ${ }^{1}$, Maria Isabel Queiroz ${ }^{2}$, Eduardo Jacob-Lopes ${ }^{1}$
}

\author{
${ }^{1}$ Food Science and Technology Department, Federal University of Santa Maria \\ (UFSM), 97105-900, Santa Maria- RS, Brazil \\ 2 School of Chemistry and Food, Federal University of Rio Grande (FURG), 96201- \\ 900, Rio Grande- RS, Brazil \\ E-mail: jacoblopes@pq.cnpq.br
}

\begin{abstract}
Biodiesel derived from microalgae has several benefits over other resources, such as oil productivity. Many microalgae greatly exceeds the best oil producing crops. Nonetheless, in order to make microalgal biodiesel competitive, single-cell oil productivity evaluation is required under different process conditions. This work evaluates the potential of third generation biodiesel (3G) by microalgae Aphanothece microscopica Nägeli cultivate heterotrophically in agro-industrial wastewaters (fish processing, rice parboiling and dairy processing). The results indicate that the single-cell oil productivities reached $0.05,0.12$ and $0.49 \mathrm{~g}_{\text {lipid }} / \mathrm{L}$.day for cultivations in fish processing, rice parboiling and dairy processing wastewater, respectively. These values are comparable to oil productivities obtained currently with soybean, demonstrating the potential of microalgae as matrix for oil production for biofuels.
\end{abstract}

\section{INTRODUCTION}

In recent years, several researchers have attempted to use single cell oil (SCO), whose lipid composition is similar to that of traditional vegetable oils, as alternatives for biodiesel production because of the current energy crisis. According to Thajuddin (2005) another fact attracting interest in these microorganisms is that they are characterized by high growth rates, thus determining technological and commercial advantages when compared to conventional techniques of producing these nutrients.

In addition to oils, as shown by Sánchez Mirón et al. (2003) microalgal biomass contains significant quantities of proteins, carbohydrates and other nutrients. Therefore, the residual biomass from biodiesel production processes can be used potentially as animal feed. Some of the residual biomass may be used to produce methane by anaerobic digestion, for generating the electrical power necessary for running the microalgal biomass production facility. Excess power could be sold to defray the cost of producing biodiesel. 
Today, the potential value of microalgae for the production of biofuels is widely recognized. Biodiesel from microalgae biotechnology is an alternative to petrodiesel and biodiesel obtained from oil crops, and in accordance with Queiroz et al. (2011) the culture conditions of microalgae can be optimized in order to maximize lipid synthesis.

Jacob-Lopes (2009) demonstrated that the closed photobioreactores, based on photosynthetic $\mathrm{CO}_{2}$ conversion, are limited by engineering related factors, since design and scale-up methodologies are poorly developed. Factors such as photobioreactor configuration and material construction are considered the main difficulties. On the other hand, studies of Gressel (2008) showed that the open pound technology is limited by biological factors such as organism survival, growth and lipid content, carbon dioxide uptake, light utilization, seasonality, harvest, and biosafety of transgenics.

These questions are related mainly to photosynthetic oil production. An alternative process is based on the heterotrophic metabolism of certain microalgae species in which the organic carbon source is assimilated in the absence of light. Li et al. (2013) reported that these processes can be conducted in conventional reactor configurations such as stirred tank and bubble column reactors, eliminating some of the disadvantages of photosynthetic microalgae cultivation. Moreover, the organic carbon source can be obtained from agro-industrial wastes. This type of substrate provides an economically feasible source of nutrients for microalgae cultures.

In accordance with Queiroz et al. (2007) and Voltolina et al. (1998) many microalgae species have been used to convert various industrial wastes into biomass. Another advantage shown by Miao and $\mathrm{Wu}$ (2006) of heterotrophic metabolism is that growth rates and biomass productivity can be substantially superior to those obtained in photosynthetic cultivation. Thus, considering that the number of microalgae species capable of accumulating a quantity of oil corresponding to more than about $20 \%$ of their biomass weight is relatively small in comparison with the total number of species, this productivity gain can be a differential factor.

It is obvious that SCO will play a more critical role in the future, and low-cost substrates for SCO production will play a key role in the industrialization of SCO production. Meng et al. (2009) and Ratledge and Cohen (2008) have reviewed SCO and its production over the past decades however, few have focused on substances that are used for SCO production.

In this regard, the aim of this work is to evaluate the potential of third generation biodiesel (3G) by microalgae Aphanothece microscopica Nägeli cultivate heterotrophically in agro-industrial wastewaters (fish processing, rice parboiling and dairy processing).

\section{MATERIAL AND METHODS}

A monoculture of Aphanothece microscopica Nägeli (RSMan92), originally isolated from the Patos Lagoon estuary, located in the state of Rio Grande do Sul, Brazil $\left(32^{\circ} 01^{\prime} \mathrm{S}-52^{\circ} 05^{\prime} \mathrm{W}\right)$ was used. Stock cultures were propagated and maintained in a synthetic BG11 medium (Rippka et al., 1979). The incubation conditions used were $25^{\circ} \mathrm{C}$, photon flux density of $15 \mu \mathrm{mol} . \mathrm{m}^{-2} . \mathrm{s}^{-1}$, and a photoperiod of $12 \mathrm{~h}$. 
Measurements were made in a bubble column bioreactor. The system was built with a thickness of $4 \mathrm{~mm}$, an internal diameter of $10 \mathrm{~cm}$, a height of $100 \mathrm{~cm}$, and a nominal working volume of $4.5 \mathrm{~L}$. The dispersion system for the reactor consisted of a $1.5 \mathrm{~cm}$ diameter air diffuser located in the center of the column.

The experiments were carried out in bioreactors operating in intermittent regime, fed with 5L of wastewater (fish processing, rice parboiling and dairy processing). The experimental conditions were as follows: initial cell concentration of $0.1 \mathrm{~g} / \mathrm{L}$, isothermal reactor operating at a temperature of $25^{\circ} \mathrm{C}, \mathrm{pH}$ adjusted to 7.6 , constant aeration of 1 VVM (volume of air per volume of wastewater per minute), and the absence of light.

Samples were collected aseptically in a laminar flow hood previously sterilized. The cellular concentration was monitored every 24 hours during the growth phase of microorganism and the lipid content of microalgal biomass was determined at the end of cultivations. The experiments were performed in duplicate and kinetic data refer to the average of four repetitions.

The cell concentration was gravimetrically evaluated by filtering a known volume of culture medium through a $0.45 \mu \mathrm{m}$ membrane filter (Millex FG ${ }^{\circledR}$, Billerica-MA, USA), drying at $60^{\circ} \mathrm{C}$ for $24 \mathrm{~h}$. The lipid fraction was extracted from the biomass by the Bligh and Dyer (1959) method.

Biomass data were used to calculate the maximum specific growth rate $\left(\ln \left(X / X_{0}\right)=\mu_{\text {max. }} \mathrm{t}\right)$, where $X$ is the final cell concentration $(\mathrm{mg} / \mathrm{L}), X_{0}$ is the initial cell concentration $(\mathrm{mg} / \mathrm{L}), \mu_{\max }$ is the maximum specific growth rate $\left(\mathrm{d}^{-1}\right)$ and $\mathrm{t}$ is time $(\mathrm{d})$, and to calculate the biomass productivity $\left(\mathrm{P}_{X}=\mu \mathrm{X}\right)$. The lipid content of the biomass was used to estimate the lipid productivity $\left(\mathrm{P}_{\mathrm{L}}=\mathrm{P}_{\mathrm{X}} \mathrm{L}\right)$, where $\mathrm{P}_{\mathrm{X}}$ is the biomass productivity $(\mathrm{mg} / \mathrm{L} . \mathrm{d})$ and $\mathrm{L}$ is the lipid content of the biomass (\%).

\section{RESULTS AND DISCUSSION}

\subsection{Screening of Substrates for Lipid Production}

To evaluate the performance of the potential of third generation biodiesel (3G) by microalgae Aphanothece microscopica Nägeli cultivate heterotrophically in agroindustrial wastewaters (fish processing, rice parboiling and dairy processing), were initially compared. The growth data obtained in these experiments are shown in Table 1.

Table 1. Growth data on Aphanothece microscopica Nägeli in different wastewaters

\begin{tabular}{c|c|c|c}
\hline Wastewaters & $\begin{array}{c}\mu m a ́ x \\
(\mathbf{d}-\mathbf{1})\end{array}$ & $\begin{array}{c}\text { Xmáx } \\
(\mathbf{g} / \mathbf{L})\end{array}$ & $\begin{array}{c}\text { Px } \\
(\mathbf{g} / \mathbf{L . d})\end{array}$ \\
\hline $\begin{array}{c}\text { fish } \\
\text { processing }\end{array}$ & 1.18 & 0.55 & 0.36 \\
\hline $\begin{array}{c}\text { rice } \\
\text { parboiling }\end{array}$ & 2.64 & 0.57 & 1.51 \\
\hline $\begin{array}{c}\text { dairy } \\
\text { processing }\end{array}$ & 8.64 & 0.84 & 3.85 \\
\hline
\end{tabular}

$\mu_{\text {máx }}$, maximum specific growth rate; $\mathrm{X}_{\text {máx }}$, maximum cellular concentration $\mathrm{P}_{\mathrm{X}}$, biomass productivity. 
The specific growth rate, $\mu$, is a measure of how quickly a microbial population is growing. High values of $\mu$ are indicative of high microbial growth rates. This kinetic parameter determines the maintenance of the steady state in biological reactors operated at a constant volume. The values of maximum specific growth rate ( $\mu$ max) show that the use of dairy processing wastewater $\left(8.64 \mathrm{~d}^{-1}\right)$ or rice parboiling wastewater $\left(2.64 \mathrm{~d}^{-1}\right)$ improved the cell growth rate, since the maximum specific growth rates obtained were higher than those reached in the fish processing wastewater $\left(1.18 \mathrm{~d}^{-1}\right)$. In addition, the analysis of kinetic growth data indicates a higher maximum specific growth rates and biomass productivities than those usually reported in photosynthetic cultures. In optimized conditions Jacob-Lopes et al. (2008) and Jacob-Lopes et al. (2009) for $A$. microscopica Nägeli cultivated photosynthetically in a bubble column reported values of 0.81 day $^{-1}$ and $0.77 \mathrm{~g} / \mathrm{L}$ day for maximum specific growth rate and biomass productivity, respectively, showing a superior performance of this cyanobacterium when cultivated heterotrophically.

The use the of microalgal biomass as feedstock for biodiesel production is a current field of application of microalgae biotechnology where high lipid productivities are required for the tecno-economic success of the process. With this in mind, lipid content and lipid productivity at different agro-industrial wastewaters are presented in Table 2.

Table 2. Lipid composition and lipid productivities at different conditions

\begin{tabular}{c|c|c}
\hline Wastewaters & Lipid & $\mathbf{P}_{\mathbf{L}}$ \\
$(\boldsymbol{\%} \mathbf{w t})$ & $(\mathbf{g} / \mathbf{L . d})$ \\
\hline $\begin{array}{c}\text { fish } \\
\text { processing }\end{array}$ & 13.8 & 0.05 \\
\hline $\begin{array}{c}\text { rice } \\
\text { parboiling }\end{array}$ & 7.9 & 0.12 \\
\hline $\begin{array}{c}\text { dairy } \\
\text { processing }\end{array}$ & 12.65 & 0.49 \\
\hline
\end{tabular}

Lipid, lipid content; $\mathrm{P}_{\mathrm{L}}$, lipid productivity.

Ratledge and Cohen (2008) explain that the lipid productivity is the main criterion for selection of the operational conditions in bioreactors for single-cell oil (SCO) production. In general, biomass productivity and lipid content are inversely related, a fact that has its rationale in the high metabolic cost of lipid biosynthesis. Sheenan et al. (1998) report that high biomass productivity and high lipid content, the desired traits for single-cell oil production from microalgae, are mutually exclusive. The best lipid producer has to combine biomass productivity and lipid content. According to Ratledge (2002) an inherited disadvantage of the physiological stress for accumulating high lipid content in microbial cells is associated with reduced cell division. Since lipids are intracellular products, overall lipid productivity is the product of cell lipid content multiplied by biomass productivity. Overall lipid/energy productivity will therefore be compromised, due to lowered biomass productivity. The results obtained in this study show that lipid content at cultivations in fish processing $(13.8 \%)$ was than doubled 
when compared with lipid content cultivations in rice parboiling (7.9\%). However, lipid productivity at a dairy processing wastewater $(0.487 \mathrm{~g} / \mathrm{L} . \mathrm{d})$ is almost 10 times higher than in fish processing wastewater $(0.05 \mathrm{~g} / \mathrm{L} . \mathrm{d})$, suggesting that the biomass productivity and lipid content are inversely related.

\subsection{Crops Vs. Microalgae as Biodiesel Feedstocks}

As stated by Demirbas (2011) more than 95\% of biodiesel sources are first generation agricultural edible crop oils. First generation biofuels have a great impact on food security and have the potential to increase the cost of food crops such as soybean thus also making biodiesel production more expensive.

Feng et al. (2011) have shown a available alternative, in terms of social and economic acceptability and greater energy security, microalgal oil is regarded as third generation biofuels source. Algal productivities can be twenty times that of oilseed crops on a per hectare basis and is thus a more viable alternative.

In this case, the production of third generation biodiesel is considered as a real option in the field of conversion of agro-industrial waste for the production of biofuels. An example of the feasibility of this technology replacing processes that use plants is shown in Figure 1.

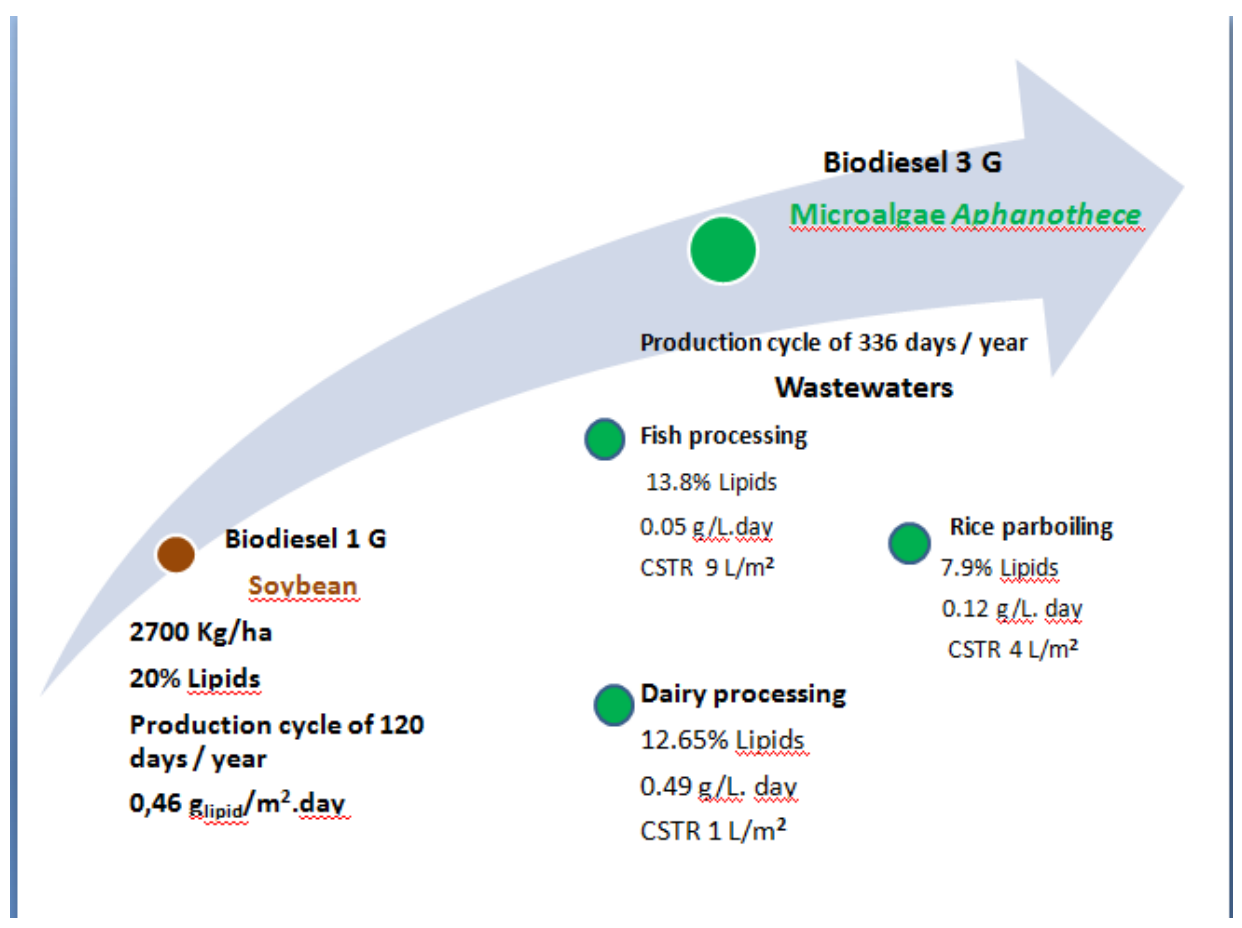

FIGURE 1. Crops Vs. Microalgae

The average yield reported by CONAB (2014) for soybean oil was around $0.46 \mathrm{~g}_{\text {lipid }} / \mathrm{m}^{2}$.day, taking a production cycle of 120 days/year. In this study, it was shown that the lowest production was $0,05 \mathrm{~g} / \mathrm{L}$.day (obtained through fish processing wastewater). It shows that equivalence production is easily achieved using a bioreactor operated continuously (CSTR) for $9 \mathrm{~L} / \mathrm{m}^{2}$. Considering an annual production cycle of 
336 days/year, this equivalence would occur in a bioreactor only $3 \mathrm{~L} / \mathrm{m}^{2}$. In this case, if work with the most productive process that used dairy processing wastewater $(0.49 \mathrm{~g} /$ L.day), this equivalence is overcome with a bioreactor $1 \mathrm{~L} / \mathrm{m}^{2}$. Hence, it is clearly shown the potential to exploit this technological route for the production of raw materials oil.

\section{CONCLUSIONS}

According to observation in this study, it is interesting to note that microalgal cells grow faster and provide a higher yield of biomass and lipid in agro-industrial wastewaters, these values have the potential to exceed oil productivities obtained currently with soybean, demonstrating the potential of microalgae as matrix for oil production for biofuels.

\section{REFERENCES}

Bligh EG, Dyer JW. A Rapid method of total lipid extraction and purification. Can J Biochem Physiol 1959;37:911-7.

Brazilian Supplying Company - CONAB, Available: http:// www.conab.gov.br (2014).

Demirbas MF. Biofuels from algae for sustainable development. Appl Energy 2011;88:3473-80. Feng Y, Li C, Zhang D. Lipid production of Chlorella vulgaris cultured in artificial wastewater medium. Bioresour Technol 2011;102:101-5.

Gressel J. Transgenics are imperative for biofuel crops. Plant Sci 2008; 174:246-263.

Huang C, X.F. Chen, L. Xiong, X.D. Chen, L.L. Ma, Y. Chen. Single cell oil production from low-cost substrates: the possibility and potential of its industrialization. Biotech Advances 31 (2013) 129-139.

Jacob-Lopes E, Revah S, Shirai K, Hernandez S, Franco TT. Development of operational strategies to remove carbon dioxide in photobioreactors. Chem Eng J. 2009;153:120-6.

$\mathrm{Li} \mathrm{X}, \mathrm{H} . \mathrm{Xu}, \mathrm{Q}$. Wu. Large-scale biodiesel production from microalga Chlorella protothecoides through heterotrophic cultivation in bioreactors. Biotechnol Bioeng, 98 (2007), pp. 764-771.

Li Y, Wang B, Wu N, Lan CQ. Effects of nitrogen sources on cell growth and lipid production of Neochloris oleoabundans. Applied Microb. and Biotech. 2008;81(4):629-36.

Meng X, Yang JM, Xu X, Zhang L, Nie QJ, Xian M. Biodiesel production from oleaginousmicroorganisms. Renew Energy 2009;34:1-5.

Miao X, Q. Wu. Biodiesel production from heterotrophic microalgae oil. Bioresour Technol, 97 (2006), pp. 841-846.

N. Thajuddin, G. Subramanian, Cyanobacterial biodiverty and potencial applications in biotechnology, Curr. Sci. 89 (2005) 47-57.

Queiroz et al./ Apllied Energy 88 (2011) 3438-3443. 
Queiroz M.I, E. Jacob-Lopes, L.Q. Zepka, R. Bastos, R. Goldbeck. The kinetics of the removal of nitrogen and organic matter from parboiled rice effluent by cyanobacteria in a stirred batch reactor. Bioresour Technol, 98 (2007), pp. 2163-2169.

Ratledge C, Cohen Z. Microbial and algal oils: do they have a future for biodiesel or as commodity oils. Lipid Technol 2008;20:155-60.

Ratledge C, Regulation of lipid accumulation in oleaginous micro-organisms. Biochem Soc Trans 2002; 30: 1047-50.

Rippka R, Deruelles J, Waterbury JB, Herdman M, Stanier RY. Generic assignments strain histories and properties of pure cultures of cyanobacteria. J Gen Appl Microbiol 1979; 111:0161.

Sánchez Mirón A, Cerón García M-C, Contreras Gómez A, García Camacho F, Molina Grima E, Chisti Y. Shear stress tolerance and biochemical characterization of Phaeodactylum tricornutum in quasi steady-state continuous culture in outdoor photobioreactors. Biochem Eng J. 2003;16:287-97.

Voltolina D, B. Cordero, M. Nieves, L.P. Soto. Growth of Scenedesmus sp in artificial wastewater. Bioresour Technol, 68 (1998), pp. 265-268. 